\title{
Left ventricular morphology and diastolic function in uraemia: echocardiographic evidence of a specific cardiomyopathy
}

\author{
L Facchin, G Vescovo, G Levedianos, L Zannini, M Nordio, S Lorenzi, G Caturelli, \\ G B Ambrosio
}

\begin{abstract}
Objective-To see whether cardiac morphological and functional abnormalities in uraemic patients are determined by high blood pressure or if they are an expression of a specific cardiomyopathy. Design-Cross sectional study.

Setting-City general hospital in Italy. Subjects-35 uraemic patients receiving haemodialysis (17 men, 18 women; mean age $60.3(11 \cdot 2)$; mean duration of dialysis 52 months) were selected from the 64 patients in Venice who were receiving dialysis; subjects with diabetes, haemochromatosis, valvar dysfunction, regional dyskinesias, and pericarditis were excluded. 19 control normotensive subjects (6 men and 13 women), matched for age.

Main outcome measures-Echocardiographic measurements of left atrium, left ventricular end diastolic and end systolic volume, aortic root diameter, posterior wall and interventricular septum thickness, left ventricle mass index, and ejection fraction in controls and in patients according to whether they were normotensive (five men, eight women) or hypertensive (12 men, 10 women) on 48 hour ambulatory monitoring; left ventricular diastolic function by Doppler ultrasonography.
\end{abstract}

Results-Mean systolic and diastolic pressures, daytime systolic and diastolic pressures, and night time systolic and diastolic pressures were significantly higher in the hypertensive patients than in the normotensive patients. The normotensive patients had similar blood pressures to the controls. Left ventricular mass correlated significantly with the mean diastolic pressure and mean night time systolic and diastolic pressures. Parathyroid hormone concentrations were similar in the two groups of patients. Diastolic relaxation was impaired to the same degree in the two groups of patients. Parameters of diastolic function showed no relation to left ventricular mass, which was significantly higher in the hypertensive than in the normotensive patients.

Conclusions-Uraemia is likely to induce specific changes in the relaxation properties of the myocardium. These changes are responsible for the impaired diastolic function independently of blood pressure, degree of hypertrophy, and metabolic changes, which suggests the existence of a specific cardiomyopathy. Hypertension remains a determinant of left ventricular mass.

\section{(Br Heart F 1995;74:174-179)}

Keywords: left ventricular morphology; diastolic function; uraemia; cardiomyopathy

Haemodialysis for chronic renal failure still carries high mortality (10\% per year). Cardiovascular events are the main cause of death $(50-60 \%$ against $15 \%$ in control populations). ${ }^{1}$ Accelerated coronary atherosclerosis, which has been claimed to be linked to lipid abnormalities, high blood pressure, diabetes, altered oxygen delivery at cellular level, and to an unknown uraemic factor, seems to be closely related to this excessive mortality. ${ }^{23}$

The natural course of disease in these patients is also characterised by congestive heart failure, possibly as a result of a specific uraemic cardiomyopathy. ${ }^{34}$ Several metabolic, ionic, hormonal, and biochemical factors have been suggested as the cause of this cardiomyopathy. ${ }^{4}$ Hyperparathyroidism may play an important part in the pathogenesis of ventricular dysfunction in uraemic patients, by determining inadequate left ventricular hypertrophy ${ }^{6}$ or by inducing low ventricular output and consequent failure and perhaps acting as a myocardial depressant. ${ }^{7}$ Recently, Horl and Riegel suggested that secondary hyperparathyroidism does not seem to be a clinically relevant myocardial depressant factor in uraemia, and they suggested the existence of a myocardial depressant factor of molecular weight between 10000 and 30000 daltons. $^{8}$

The other factor invoked to explain ventricular hypertrophy and dysfunction is hypertension. In patients undergoing haemodialysis the prevalence of isolated systolic and systodiastolic hypertension is fairly high. Simon et al reported a prevalence of $13 \%$ and $15 \%$ respectively. ${ }^{9}$ Parfrey and Harnett showed that systolic hypertension in uraemic patients is an independent risk factor for the development of left ventricular hypertrophy. ${ }^{10}$ In essential hypertension both systolic and diastolic high blood pressure determine left ventricular hypertrophy and eventually the systolic dysfunction that results in overt cardiac failure. ${ }^{11}$ However, the relation between hypertension, left ventricular hypertrophy, and diastolic function is not yet clear. In fact, 
correlations between blood pressure measured in a doctor's surgery and early alterations in diastolic function have not been found in essential hypertension, although a correlation was found with blood pressures monitored over 24 hours. ${ }^{1213}$ Alterations in diastolic function are correlated with the progression of left ventricle hypertrophy, ${ }^{14}$ except in isolated systolic hypertension, where this correlation cannot always be found. ${ }^{15}$

To verify whether a uraemic cardiomyopathy with specific myocardial features independent from hypertensive heart disease exists, ${ }^{16}$ we investigated the morphological profile and the diastolic function pattern of the left ventricle in a selected group of uraemic patients undergoing chronic haemodialysis by means of $M$ mode, cross sectional, and Doppler echocardiography. A group of normal subjects with similar demographic characteristics was also studied.

\section{Patients and methods}

Sixty four patients receiving haemodialysis long term for chronic renal failure underwent echocardiographic and doppler assessment as screening for this project. They were all in sinus rhythm with neither physical nor laboratory signs of congestive heart failure. Medical history was negative for other disorders such as diabetes and haemochromatosis. Nineteen healthy normotensive subjects were chosen as controls from among the paramedical staff of this hospital; they were matched for age with the patients and had normal fasting glucose concentrations, lipid profiles, renal function, and packed cell volumes. Patients with pericardial effusion, constrictive pericarditis, haemodynamically significant valvar dysfunction, and regional dyskinesias were excluded. Thus the sample studied comprised only 35 (17 men, 18 women) of the 64 uraemic patients $(54 \cdot 7 \%$ of the sample).

All the patients had their blood tested; parathyroid hormone concentration was measured by means of a two site chemiluminescent immunometric assay of the entire molecule.

The presence of coronary heart disease was excluded by recalling the medical history and by means of electrocardiography and 24 hour Holter monitoring in which the theoretical submaximal heart rate was reached. Echo measurements were carried out during the short interdialytic interval (48 hours), exactly 24 hours after the end of the last dialysis. All the measurements were performed with a HP SONOS $1000,2.5$ and $3.5 \mathrm{mHz}$ probes. The standardised method of Feigenbaum was used. ${ }^{17}$ Transmitral flow was assessed through an apical two or four chambers approach. Volume sample (4-5 mm length) was positioned within the mitral orifice at the level of the leaflets apex. Colour Doppler and signal frequency were used as a guide to align sampling with the direction of flow.

With a parasternal short axis approach we measured left ventricular end diastolic and end systolic diameters, interventricular septum and posterior wall thicknesses, and systolic left atrium diameter. Aortic root diameter was measured with a parasternal long axis approach. Cardiac mass was measured by using the Deveraux equation. ${ }^{18}$ Ejection fraction was measured with the modified Simpson method ${ }^{19}$ in an apical two or four chamber approach. We also calculated the following Doppler parameters: maximal velocities of $E$ and $A$ waves $(V \operatorname{maxE}, \operatorname{Vmax} A)$ : acceleration and deceleration of $E$ and $A$ waves (AccE, DecE, AccA, and DecA); acceleration and deceleration times of $E$ and $A$ waves (DecTE, DecTA); the ratio of velocities in $A$ and $E$ waves (A/E); area of waves $E$ and $A(S E, S A) ; S A / S E+S A$; and isovolumic relaxation time. ${ }^{17}{ }^{20}$ Echo measurements were performed by a cardiologist and data analysed by two well trained observers; intrasample and intersample variability were low (coefficient of variation $3 \%$ ). Each measurement was done twice, and the average of the results obtained over three consecutive cardiac cycles was used.

Blood pressure was measured before and after each haemodialysis, but patients were allocated to the hypertensive or normotensive group by using the data from the 48 hours of continuous ambulatory monitoring, which was carried out in the short time between dialysis. Ambulatory monitoring data were also used because they correlate more strongly than blood pressure measured in a surgery with the prevalence of cardiovascular complications such as cardiac hypertrophy. ${ }^{12} \mathrm{~A}$ Spacelabs 90207 instrument was used for this purpose. Patients with a mean hourly blood pressure that was always lower than 160 or 95 $\mathrm{mm} \mathrm{Hg}$, or both, were considered to be normotensive. Patients with a mean hourly blood pressure greater than or equal to 160 or 95 $\mathrm{mm} \mathrm{Hg}$, or both, were considered to be hypertensive. Patients who had normal blood pressures after dialysis but pressures increased afterwards to mean hourly values greater than 160 or $95 \mathrm{~mm} \mathrm{Hg}$, or both, were considered to have volume dependent hypertension and were included in the hypertensive group.

Statistical analysis was carried out by means of a BMDP statistical package. ${ }^{21}$ One way analysis of variance was used to compare the three groups of patients studied, while analysis of covariance was used for the indices of cardiac hypertrophy in the two subgroups of uraemic patients. Within the uraemic patients linear regression analysis was used to correlate cardiac mass with the mean systolic and diastolic blood pressures over 48 hours and with the diurnal and nocturnal values; cardiac mass with indices of diastolic function; ambulatory blood pressures with parameters of diastolic function; parathyroid hormone concentrations with indices of diastolic function and ambulatory blood pressure over 48 hours. A two way analysis of variance was carried out in uraemic patients to see whether differences in cardiac mass were related to sex. 
Table 1 Clinical and laboratory data on uraemic patients. Values are mean (SD)

\begin{tabular}{|c|c|c|c|}
\hline & $\begin{array}{l}\text { All } \\
(17 \text { men, } 18 \text { women })\end{array}$ & $\begin{array}{l}\text { Normotensive } \\
(5 \text { men, } 8 \text { women })\end{array}$ & $\begin{array}{l}\text { Hypertensive } \\
(12 \text { men, } 10 \text { women })\end{array}$ \\
\hline Age (years) & $60(14)$ & $60(14)$ & $59(16)$ \\
\hline Duration of dialysis (months) & $52(54)$ & $43(40)$ & $60(57)$ \\
\hline \multicolumn{4}{|l|}{ Measurements before dialysis } \\
\hline Haemoglobin $(\mathrm{g} / \mathrm{l})$ & $85(4)$ & $85(3)$ & $86(4)$ \\
\hline Packed cell volume (\%) & $30 \cdot 4(4 \cdot 3)$ & $30 \cdot 5(4 \cdot 1)$ & $30 \cdot 2(4 \cdot 7)$ \\
\hline Sodium $(\mathrm{mEq} / \mathrm{l})$ & $139(1 \cdot 3)$ & $138(1 \cdot 3)$ & $139(1 \cdot 1)$ \\
\hline Potassium (mEq/l) & $5 \cdot 2(0 \cdot 5)$ & $5 \cdot 3(0.4)$ & $5 \cdot 1(0 \cdot 5)$ \\
\hline Calcium $(\mathrm{mg} / \mathrm{l})$ & $94(20)$ & $93(21)$ & $95(98)$ \\
\hline Blood urea nitrogen $(\mathrm{mg} / \mathrm{l})$ & $846(167)$ & $848(167)$ & $855(172)$ \\
\hline Creatinine $(\mathrm{g} / \mathrm{l})$ & $117(29)$ & $116(30)$ & $110(28)$ \\
\hline Phosphataemia (g/l) & $52(18)$ & $49(16)$ & $59(18)$ \\
\hline Alkaline phosphatase (IU/l) & $104 \cdot 1(62 \cdot 4)$ & $103 \cdot 7(72 \cdot 8)$ & $106 \cdot 6(50 \cdot 6)$ \\
\hline Albumin $(g / 1)$ & $43(4)$ & $43(5)$ & $43(3)$ \\
\hline Parathyroid hormone (nmol/l) & $238 \cdot 3(253 \cdot 6)$ & $229.9(275.9)$ & $247.9(207 \cdot 4)$ \\
\hline $\mathrm{KT} / \mathrm{V}$ & $1.01(0.26)$ & $1.06(0.3)$ & $0.93(0 \cdot 14)$ \\
\hline
\end{tabular}

$\mathrm{K}=$ urea clearance, $\mathrm{T}=$ time of dialysis, $\mathrm{V}=$ urea volume distribution.

Table 2 Mean (SD) blood pressures ( $\mathrm{mm} \mathrm{Hg}$ ) in controls and uraemic patients

\begin{tabular}{|c|c|c|c|}
\hline & \multirow[b]{2}{*}{$\begin{array}{l}\text { Controls } \\
(6 \text { men, } 13 \text { women })\end{array}$} & \multicolumn{2}{|l|}{ Patients } \\
\hline & & $\begin{array}{l}\text { Normotensive } \\
\text { ( } 5 \text { men, } 8 \text { women })\end{array}$ & $\begin{array}{l}\text { Hypertensive } \\
(12 \text { men, } 10 \text { women })\end{array}$ \\
\hline $\begin{array}{l}\text { Systolic } \\
\text { Diastolic } \\
\text { Daytime: }\end{array}$ & $\begin{array}{r}113.8(5 \cdot 4) \dagger \\
67.9(4 \cdot 6) \dagger\end{array}$ & $\begin{array}{c}110.4(13.5) \\
64.0(8.5)\end{array}$ & $\begin{array}{r}145 \cdot 1(13 \cdot 5)^{\star} \ddagger \\
86 \cdot 7(11 \cdot 1)^{\star} \ddagger\end{array}$ \\
\hline $\begin{array}{l}\text { Systolic } \\
\text { Diastolic }\end{array}$ & $\begin{array}{r}115.8(6.4) \dagger \\
69.9(5.8) \dagger\end{array}$ & $\begin{array}{c}111 \cdot 7(13 \cdot 0) \\
65 \cdot 5(8 \cdot 1)\end{array}$ & $\begin{array}{r}145 \cdot 9(14 \cdot 5)^{\star} \ddagger \\
87 \cdot 4(11 \cdot 4)^{\star} \ddagger\end{array}$ \\
\hline $\begin{array}{l}\text { Night time: } \\
\text { Systolic } \\
\text { Diastolic }\end{array}$ & $\begin{array}{r}110 \cdot 5(5 \cdot 6) \dagger \\
65 \cdot 1(4 \cdot 7) \dagger\end{array}$ & $\begin{array}{c}108 \cdot 2(14 \cdot 1) \\
61 \cdot 6(9 \cdot 1)\end{array}$ & $\begin{array}{r}144 \cdot 6(15 \cdot 8)^{\star} \ddagger \\
86 \cdot 0(15 \cdot 1)^{\star \star} \ddagger\end{array}$ \\
\hline
\end{tabular}

${ }^{\star} \mathrm{P}<0.001 v$ uraemic normotensive patients. ${ }^{\star \star} \mathrm{P}<0.01 v$ uraemic normotensive patients.

$\dagger \mathrm{P}=\mathrm{NS} v$ uraemic normotensive patients. $\ddagger \mathrm{P}<0.001 v$ controls.

\section{Results}

Table 1 shows the baseline characteristics of the uraemic patients. Their mean age was $60 \cdot 3(14 \cdot 2)$ years and they had received dialysis for a mean of 52 months (range 10-76). $66 \%$ of the patients were treated with hr-erythropoietin to achieve a target haemoglobin concentration of $8.5 \mathrm{~g} / 1$ (packed cell volume $30 \%)$. According to the results of blood pressure monitoring over 48 hours, 22 patients (12 men, 10 women) were categorised as being hypertensive and 13 patients (five men, eight women) as normotensive. Controls (six men and 13 women) had a mean age of 57.5 $(8 \cdot 4)$ years.

The original nephropathy in the 35 uraemic patients was undetermined nephropathy (eight patients), nephroangiosclerosis (nine), rapidly progressive glomerulonephritis (two), interstitial nephropathy (five), obstructive nephropathy (two), chronic glomerulonephritis

Table 3 Mean (SE) echocardiographic data

\begin{tabular}{|c|c|c|c|c|c|}
\hline & \multirow[b]{2}{*}{ Controls } & \multicolumn{2}{|c|}{ Patients with uraemia } & \multirow[b]{2}{*}{$F$} & \multirow[b]{2}{*}{ Pvalue } \\
\hline & & Normotensive & Hypertensive & & \\
\hline $\begin{array}{l}\text { LVEDD (mm) } \\
\text { LVESD (mm) } \\
\text { IVS (mm) } \\
\text { PWT (mm) } \\
\text { ARD (mm) } \\
\text { LAD (mm) } \\
\text { LVM (g) } \\
\text { EF (\%) }\end{array}$ & $\begin{array}{c}48 \cdot 1(0.6) \\
31.0(0.5) \\
9.4(0.3) \\
8 \cdot 7(0.3) \\
29 \cdot 1(0.9) \\
33.8(0.8) \\
121(17) \\
61(11)\end{array}$ & $\begin{array}{c}52 \cdot 9(1 \cdot 1)^{\star} \\
31 \cdot 8(1 \cdot 0)^{\star} \\
12 \cdot 3(0 \cdot 4)^{\star} \\
12 \cdot 0(0.4)^{\star} \\
36 \cdot 1(0 \cdot 9)^{\star} \\
37 \cdot 1(1 \cdot 0)^{\star} \\
139(24) \\
58(10)\end{array}$ & $\begin{array}{l}54(1 \cdot 3)^{\star} \\
32 \cdot 6(1 \cdot 2)^{\star} \\
14 \cdot 4(0 \cdot 3)^{\star} \dagger \\
13 \cdot 7(0 \cdot 3)^{\star} \dagger \\
34 \cdot 9(0 \cdot 7)^{\star} \dagger \\
39 \cdot 2(1 \cdot 0)^{\star} \\
163(25) \dagger \\
60(8)\end{array}$ & $\begin{array}{r}9 \cdot 11 \\
0 \cdot 74 \\
37 \cdot 14 \\
47 \cdot 26 \\
18 \cdot 34 \\
8 \cdot 54 \\
6 \cdot 35 \\
0 \cdot 30\end{array}$ & $\begin{array}{l}0.0004 \\
\text { NS } \\
0.0001 \\
0.0001 \\
0.0001 \\
0.006 \\
0.017 \\
\text { NS }\end{array}$ \\
\hline
\end{tabular}

LVEDD, Left ventricular end diastolic diameter; LVESD, left ventricular end systolic diameter IVS, interventricular septum thickness; PWT, posterior wall thickness; ARD, aortic root diameter; LAD, left atrial diameter; LVM, left ventricular mass index; EF, ejection fraction. LVM was calculated with the Deveraux equation 18

$\star$ Significantly different $v$ controls. †Significantly different $v$ uraemic normotensive patients. (six), and adult polycystic kidney disease (three) $\left(\chi^{2}=3 \cdot 61, \mathrm{NS}\right)$.

Table 2 shows the ambulatory blood pressures over 48 hours in the three groups. Control subjects had similar blood pressures to normotensive uraemic patients, but significantly lower blood pressures than the hypertensive uraemic patients $(P<0.001$ for all the variables analysed). Systolic and diastolic blood pressures were always significantly higher in the hypertensive patients than in the normotensive patients.

Multiple logistic regression analysis with hypertension as the dependent variable was not related to sex, blood urea nitrogen, creatinine concentration, phosphataemia, serum albumin concentration, parathyroid hormone concentration, serum concentrations of calcium, sodium, and potassium, packed cell volume, or $\mathrm{KT} / \mathrm{V}$ as predictors. Parathyroid hormone concentration was 229.9 (276.0) $\mathrm{nmol} / \mathrm{l}$ in the normotensive uraemic patients and $247.9(207.4) \mathrm{nmol} / \mathrm{l}$ in the hypertensive uraemic patients (normal range $5-50 \mathrm{nmol} / \mathrm{l}$ ).

Table 3 summarises the echocardiographic measurements in the three groups. Interventricular septal and posterior wall thicknesses, systolic left atrial diameter, and aortic root diameter were significantly higher in the uraemic patients $(P<0.0001)$. Left ventricular end diastolic diameter and cardiac mass were also significantly different $(P<$ 0.001 and $P=0.017$ respectively).

No significant differences were found in ejection fraction. When the two subgroups of hypertensives and normotensives were compared, only the interventricular septal and posterior wall thicknesses and cardiac mass were significantly higher in the first group. There was no overlap between uraemic and control patients in interventricular septal and posterior wall thicknesses. Overlap was almost completely absent between hypertensive and normotensive patients undergoing dialysis. Table 4 shows the various parameters of left ventricular diastolic function. VmaxA, DecE, AccA, DecTE, DecTA, A/E, SA, SA/SA + SE, and isovolumic relaxation time were significantly higher in uraemic patients than controls.

A multiple analysis of covariance was carried out to see whether differences in diastolic function between hypertensive and normotensive patients undergoing dialysis could be accounted for by the different degree of hypertrophy. Diastolic function parameters were therefore analysed with left ventricular mass index, and posterior wall and interventricular septal thicknesses used as covariates. The two subgroups of patients did not differ in VmaxA, DecE, DecTE, or isovolumic relaxation. Only SA was significantly greater in the normotensive patients. Thus, once the effect of hypertrophy has been accounted for, the two groups of patients have comparable diastolic function, except SA.

No correlation was found between the length of time receiving dialysis and any of the echocardiographic parameters analysed.

There was a significantly positive correla- 
Table 4 Mean (SE) transmitral flow Doppler measurements

\begin{tabular}{|c|c|c|c|c|c|}
\hline & \multirow[b]{2}{*}{ Controls } & \multicolumn{2}{|c|}{ Patients with uraemia } & \multirow[b]{2}{*}{$F$} & \multirow[b]{2}{*}{$P$ value } \\
\hline & & Normotensive & Hypertensive & & \\
\hline$V \max E(\mathrm{~cm} / \mathrm{s})$ & $69.0(3.2)$ & $58 \cdot 0(4 \cdot 5)$ & $59.8(3.4)$ & 2.33 & NS \\
\hline $\operatorname{AccE}(\mathrm{cm} / \mathrm{s})$ & $896.3(40 \cdot 2)$ & $847.0(90.9)$ & $1176 \cdot 0(218 \cdot 1)$ & 2.05 & NS \\
\hline $\operatorname{DecE}(\mathrm{cm} / \mathrm{s})$ & $527.7(50.9)^{\star}$ & $255 \cdot 3(38 \cdot 8)$ & $279.6(55 \cdot 3)$ & $10 \cdot 65$ & 0.001 \\
\hline $\operatorname{AccTe}(\mathrm{m} / \mathrm{s})$ & $79 \cdot 0(7 \cdot 2)$ & $81.4(5.9)$ & $73 \cdot 5(7 \cdot 5)$ & $0 \cdot 31$ & NS \\
\hline $\operatorname{DecTE}(\mathrm{m} / \mathrm{s})$ & $131 \cdot 1(8 \cdot 8)$ & $318.6(26 \cdot 1)$ & $303.1(29.0)$ & $22 \cdot 05$ & 0.001 \\
\hline$\overline{S E}(\mathrm{~cm})$ & $10.3(0.7)$ & $9.5(1.0)$ & $8.1(0.8)$ & $1 \cdot 16$ & NS \\
\hline $\operatorname{VmaxA}(\mathrm{cm} / \mathrm{s})$ & $64.7(3.8)^{\star}$ & $85 \cdot 0(3 \cdot 1)$ & $86.8(4.4)$ & 10.97 & 0.001 \\
\hline $\operatorname{AccA}(\mathrm{cm} / \mathrm{s})$ & $887.0(70 \cdot 8)^{\star}$ & $1350 \cdot 7(114 \cdot 0)$ & $1478.0(273.5)$ & $4 \cdot 4$ & 0.017 \\
\hline $\operatorname{DecA}(\mathrm{cm} / \mathrm{s})$ & $630.0(56 \cdot 7)$ & $570.9(55.0)$ & $627 \cdot 0(58 \cdot 2)$ & 0.37 & NS \\
\hline $\operatorname{AccTA}(\mathrm{m} / \mathrm{s})$ & $60 \cdot 7(5.9)$ & $74 \cdot 2(6 \cdot 7)$ & $75 \cdot 1(5 \cdot 0)$ & $1 \cdot 64$ & NS \\
\hline $\operatorname{DecTA}(\mathrm{m} / \mathrm{s})$ & $79.5(6.8)^{\star}$ & $176.0(15.4)$ & $162 \cdot 2(11 \cdot 1)$ & $18 \cdot 43$ & 0.001 \\
\hline $\mathrm{SA}(\mathrm{cm})$ & $6.4(0.5)^{\star}$ & $10.8(0.8)$ & $9.2(0.8)$ & $9 \cdot 51$ & 0.001 \\
\hline ISA & $0.40(0.02)^{\star}$ & $0.50(0.02)$ & $0.50(0.03)$ & 11.99 & 0.001 \\
\hline $\mathrm{A} / \mathrm{E}(\mathrm{cm} / \mathrm{s})$ & $1 \cdot 0(0 \cdot 1)^{\star}$ & $1 \cdot 8(0 \cdot 3)$ & $1.5(0 \cdot 1)$ & $4 \cdot 19$ & 0.02 \\
\hline IVRT $(\mathrm{m} / \mathrm{s})$ & $76.0(5 \cdot 7)^{\star}$ & $101 \cdot 2(8 \cdot 8)$ & $99 \cdot 3(7 \cdot 7)$ & $3 \cdot 44$ & 0.04 \\
\hline
\end{tabular}

One way analysis of variance was used.

VmaxE, E wave maximal velocity; AccE, E wave acceleration; DecE, E wave deceleration; AccTE, E wave acceleration time; DecTE, E wave deceleration time; SE, E wave area; VmaxA A wave maximal velocity; AccA, A wave acceleration; DecA, A wave deceleration; AccTA, A wave acceleration time; DecTA, A wave deceleration time; SA, A wave area; ISA, SA/SA + SE; $\mathrm{A} / \mathrm{E}, \mathrm{A}$ wave area/E wave area; IVRT, isovolumic relaxation time.

*Significantly different $v$ patients with uraemia. tion between left ventricular mass index and mean diastolic blood pressure over 48 hours $(P<0.05)$, average nocturnal diastolic blood pressure $(P<0.05)$, and average nocturnal systolic blood pressure $(P<0.05)$, which are considered to be indices of cardiac workload. There was no correlation between the 48 hour ambulatory blood pressure parameters and the following indices of diastolic function: SA, $\mathrm{SE}, \mathrm{SA} / \mathrm{SE}$, and isovolumic relaxation time. Similarly, no correlation was found between left ventricular mass index and interventricular septal and posterior wall thicknesses and $\mathrm{SA}, \mathrm{SE}, \mathrm{SA} / \mathrm{SE}$, and isovolumic relaxation time. Parathyroid hormone concentrations also did not correlate with these indices of diastolic function.

\section{Discussion}

Chronic renal failure is accompanied by a high prevalence of morphological and functional changes in the heart, and these can easily be detected by echocardiography. These abnormalities are responsible for the high incidence of congestive heart failure and cardiac mortality in affected patients. ${ }^{2}$ Many authors ascribed these changes to coronary heart disease or hypertension, which are both often found in uraemic patients receiving dialysis. These patients might develop a specific cardiomyopathy, secondary to their specific metabolic, biochemical, hormonal, and maybe even haemodynamic features (atrioventricular fistula). ${ }^{4-22}$ In the early phases of uraemic cardiomyopathy the interventricular septum and the posterior wall become thickened in association with appreciable dilatation of the left atrium in $40 \%$ of patients. Global dilatation of the left ventricle occurs only in the late stages, ${ }^{23}$ and some authors consider this to be the result of high blood pressure, which is often found in these subjects, ${ }^{24}$ rather than of intrinsic changes due to uraemia.

Our blood pressure data are from 48 hour monitoring; in other studies such data seem to be closely correlated to the prevalence of complications, the degree of cardiac hypertrophy, and the alterations in diastolic function. ${ }^{11-14} \mathrm{~A}$ cut off point between hypertension and normotension in uraemic patients of $160 / 90 \mathrm{~mm}$ $\mathrm{Hg}$ might seem arbitrary, but this was an attempt to include isolated systolic hypertension (defined in large clinical trials such as SHEP $^{15}$ and SYST-EUR greater than 160 $\mathrm{mm} \mathrm{Hg}$ ) and systodiastolic hypertension. A similar cut off point was adopted in a previous study using ambulatory blood pressure monitoring in patients undergoing haemodialysis. ${ }^{9}$ Our morphological data are similar to published data; in fact, uraemic patients have much thicker ventricle walls, a greater left ventricular mass, and a higher degree of dilatation. Within these patients, hypertensive subjects show a significantly higher left ventricular mass and thicker interventricular septum. However, the presence of morphological changes even in the subgroup of normotensive uraemic patients indicates that chronic renal failure or its inadequate correction by haemodialysis may have an important and independent role. Hypertension can worsen the degree of hypertrophy. Left ventricular mass correlates significantly with the average diastolic blood pressure and the mean systolic and diastolic nocturnal pressures over 48 hours, which can be considered to be good indices of cardiac workload. Patients considered normotensive in this study might have been hypertensive in the past and have therefore developed some degree of cardiac hypertrophy. If that had been the case, lowering blood pressure should none the less have produced regression in left ventricular hypertrophy. ${ }^{25-27}$ In terms of systolic dysfunction in our uraemic patients, this is present to a lesser degree than reported in other series, but this can be explained, at least in part, by the fact that we excluded all the subjects with haemodynamically significant valve dysfunction, ischaemia, and supraventricular tachyarrhythmias such as atrial fibrillation. Recently the importance of studying not only the anatomical but also the functional diastolic changes in the left ventricle have been emphasised. ${ }^{28}$ This can be easily done by means of Doppler echocardiography of transmitral flow, such data being consistent with the data obtained by other methods such as angiography and radionuclide scanning. ${ }^{29-31}$

Determinants of transmitral flow are the active relaxation of the left ventricle, myocardial stiffness, and some haemodynamic variables such as preload and afterload, atrial pressure, and ventricular pressure. Pressure and volume overload are characterised by typical modifications of the diastolic curves. ${ }^{32-33}$ Patients undergoing dialysis long term show an altered diastolic function similar to that of patients with left ventricular hypertrophy without interdialytic volume overload, though they may present with a pressure and volume overload. Transmitral flow is characterised by a dominant $\mathrm{A}$ wave with an increased isovolumic relaxation time. ${ }^{34-36}$ In clinical and experimental models the increased ventricle stiffness which accompanies left ventricular hypertrophy is mainly due to changes in the collagen 
network $^{37}$ rather than to the increased myocyte mass. ${ }^{38}$ Recent data in uraemic patients ${ }^{39}$ and rats $^{40}$ suggest that uraemia is characterised by an increased myocardial collagen content in the myocardium - so called diffuse intermyocardiocytic fibrosis-although myocyte elongation has been described. The altered diastolic function seems therefore to be linked to fibrosis. ${ }^{41}$ Lowering blood pressure by means of methyldopa, calcium channel blockers, angiotensin converting enzyme inhibitors, and canrenoate potassium ${ }^{42-44}$ in experimental models of left ventricular hypertrophy decreases left ventricular mass by reducing myocyte hypertrophy. Collagen content is also decreased and collagen phenotypes reshifted.

We therefore suggest that the altered diastolic function in our patients can be mainly ascribed to an increased myocardial stiffness since changes in the $\mathrm{A}$ wave and isovolumic relaxation time are more pronounced. Changes in myocardial function due to increased preload have a minor role. Our hypertensive and normotensive patients showed the same degree of changes in diastolic function, though they had significantly different indices of left ventricular mass and none of the diastolic parameters correlated with left ventricular mass or with blood pressures over 48 hours. These data are only partially in keeping with those reported for uraemic patients. Huting et al reported that diastolic function does not correlate with the degree of left ventricular hypertrophy, ${ }^{45}$ patients with uraemia showing impaired diastolic filling independently from left ventricular mass. However, the same group found a correlation between diastolic function and blood pressure measured in a doctor's surgery. ${ }^{46}$ Myocardial stiffness in uraemic patients seems to be complex, with many factors contributing to the development of cardiac hypertrophy. This is not the case for left ventricular mass, which correlates well with blood pressure monitored over 48 hours and therefore with cardiac workload.

We think that the increased myocardial stiffness is determined also by uraemia. In fact, we recently showed that contractility of single isolated myocytes, as well as their intrinsic speed of shortening and relaxation, is depressed in rats with chronic uraemia. These changes were not ascribed to myocyte hypertrophy since contractile proteins did not show the typical shift towards the slow myosin isoforms of the hypertrophied myocardium. We hypothesised that cardiotoxic substances produced during uraemia could slow down contraction and relaxation. ${ }^{40}$

Hyperparathyroidism may have an important role in the pathogenesis of uraemic cardiomyopathy. ${ }^{67}$ Indeed, our patients have high concentrations of parathyroid hormone regardless of their blood pressure. We found no correlations between parathyroid hormone concentration and indices of diastolic function, but we cannot say that abnormal diastolic function is not affected by parathyroid hormone. The same may be true for other variables such as haemoglobin, ions, and other metabolites, whose concentrations were almost identical in the two groups of uraemic patients. Recently, however, "uraemic cardiodepressant factors" with molecular weights between 10000 and 30000 daltons have been identified. ${ }^{8}$ Therefore specific substances may modify the composition of the interstitium, as well as metabolic factors, ions, and hormones. Further studies are needed to identify a cause and effect relation.

1 Degoulet $\mathrm{P}$, Legrain M, Aime F, Devries C, Rojas P, Jacobs C. Mortality risk factors in patients treated by chronic hemodialysis. Nephron 1982;31:103-10.

2 Parfrey PS, Harnett JD, Barre PE. The natural history of myocardial disease in dialysis patients. $\mathcal{f} \mathrm{Am}$ Soc Nephrol 1991;2:2-12.

3 Brown JH, Hunt LP, Vites NP, Short CD, Gokal R, Mallik NP. Comparative mortality from cardiovascular disease in patients with chronic renal failure. Nephrol Dial Transplant 1994;9:1136-42.

4 Drueke T, La Pailleur CI, Meilhac B, et al. Congestive cardiomyopathy in uraemic patients on long-term cardiomyopathy in uraemic pa

5 Harnett JD, Parfrey PS, Griffiths SM, Gault MH Guttman RD. Left ventricular hypertrophy in end-stage renal disease. Nephron 1988;48:107-15

6 London GM, Fabiani F, Marchais SJ. Uremic cardiomyopathy: an inadequate left ventricular hypertrophy. Kidney Int 1987;32:878-82.

7 Parfrey PS, Harnett JD, Griffiths S, Gault MH, Barre PE Guttmann RD. Low-output left ventricular failure in end-stage renal disease. Am $₹$ Nephrol 1987;7:184-91.

8 Horl WH, Riegel W. Cardiac depressant factors in renal disease. Circulation 1993;87(suppl 5):IV77-82.

9 Simon P, Ang KS, Benziane A, Cam G. Hypertension arterielle systolique isolée chez l'uremique hemodialyse. Arch Mal Coeur Vaiss 1991;84:1205-10.

10 Parfrey PS, Harnett JD. Morbidité et mortalité d'origine cardiaque dans le suivi à long terme des patients dialysés. Actualités Néephrologiques 1993;1:243-62.

$11 \mathrm{Laragh} \mathrm{JH}$. Cardiac pathophysiology and its heterogeneity in patients with established hypertensive disease. $A m \mathcal{F}$ Med 1988;84:3-11.

12 Devereux RB, Pickering TG. Relationship between ambulatory and exercise blood pressure and cardiac structure. Am Heart f 1988;116:1124-33.

13 Bongiovi S, Palatini P, Macor F, Visentin P, Pessina AC Age and blood pressure related changes in left ventricular Age and blood pressure related changes in left ventric

14 Douglas PS, Berko B, Lesh M, Reichek N. Alterations in diastolic function in response to progressive left ventricular hypertrophy. $\mathcal{F} \mathrm{Am}$ Coll Cardiol 1989;13:461-7.

15 Pearson AC, Gudipati C, Nagelhout D, Sear J, Cohen JD, Labovitz AJ. Echocardiographic evaluation of cardiac structure and function in elderly subjects with isolated systolic hypertension. $f \mathrm{Am}$ Coll Cardiol 1991;17: 422-30.

16 Kramer W, Thormann J, Huting J, Schlepper $M$ Wizemann V. Left ventricular dysfunction in terminal renal insufficiency: does this indicate "uremic cardiomyopathy"? Circulation 1988;78:364.

17 Feigenbaum $H$. Echocardiography. 3rd ed. Philadelphia: Lea and Febiger, 1981

18 Devereux RB, Reicker N. Echocardiographic determination of left ventricular mass in man: anatomic validation of the method. Circulation 1977;55:613-8.

19 Neyman AE, Doty WD. Left ventricle. In: Weiman AE ed. Cross sectional echocardiography. Philadelphia: Lea and Febiger, 1982:267.

20 Ishida Y, Meisner JS, Tsujioka K. Left ventricle filling dynamics: influence of left ventricular relaxation and left dynamics: influence of left ventricular rela

21 Dixon WJ, Brown MB, Engelman L, Jenrich RI. BMDP statistical software manual. Berkeley: University of California Press, 1990.

22 Grossmann R, Albert FW. Echokardiographische befunde bei terminal nierenisuffizienten patienten unter chronisch intermittierender dialysebehandlung. Nieren Hochdruckkrank 1984;13:410-4.

23 Parfrey PS. Cardiac and cerebrovascular disease in chronic uremia. Am $\mathcal{F}$ Kidney Dis 1993;21:77-82.

24 Huting J, Kramer W, Schutterle G, Wizemann V. Analysis of left ventricular changes associated with chronic hemodialysis: a noninvasive follow-up study. Nephron 1988;49:284-90.

25 Kobayashi H, Sano T, Tarazi R, Fouad-Tarazi FM Effects of antihypertensive drugs on heart and resistance Effects of antihypertensive drugs on heart
vessel. Cardiovasc Res 1990;24:137-43.

26 Bertocchi S, Chiariello M. Effects of antihypertensive therapy on diastolic dysfunction in left ventricula hypertrophy. $\mathcal{f}$ Cardiovasc Pharmacol 1992;19(suppl 5) 116-21.

27 Torok E, Borbas S, Lengyel M, Zorandi A. Regression of cardiac hypertrophy in hypertensive patients by long 
term treatment with isradipine. $\mathcal{f}$ Cardiovasc Pharmacol 1992;19(suppl 3):579-83.

28 Josephs W, Odenthal HJ, Lenga P, Wiechmann HW. Doppler echocardiographic description of left ventricular diastolic malfunction in chronic renal failure-actual lar diastolic malfunction in chronic renal failure-actual
characterisation of uremic cardiomyopathy. $Z$ Kardiol characterisation

29 Liguori A, Di Ieso N, Napoli C. Quadri morfologici ed indici di funzionalità cardiaca in pazienti emodializzati cronici: studio ecocardiografico. G Ital Ecografia Cardiovasc 1992;2:23-32.

30 Rokey R, Kuo LL, Zoghbi WA, Limacher MC, Quinones MA. Determination of parameters of left ventricular diastolic filling with pulsed Doppler echocardiography: comparison with cineangiography. Circulation 1985;71: 543-50.

31 Spirito P, Maron BJ, Bonow RO. Noninvasive assessment of left ventricular diastolic function: comparative analysis of Doppler echocardiography and radionuclide angiographic techniques. $¥ \mathrm{Am}$ Coll Cardiol 1986;7:518-26.

32 Appleton CP, Hayle KL, Popp RL. Relation of transmitral flow velocity patterns to left ventricular diastolic function: new insights from a combined hemodynamic and Doppler echocardiography study. $\mathcal{f} \mathrm{Am}$ Coll Cardiol 1988;12:426-40.

33 Choong CY, Abscal VM, Thomas JD. Combined influences of ventricular loading and relaxation on the transmitral flow velocity-profile in dogs measured by Doppler echocardiography. Circulation 1988;78:672-83.

34 Yamagishi T, Yuki K, Ozaki M, Kusukawa R. Effects of dialysis on left ventricular diastolic filling in patients with dialysis on left ventricular diastolic filling in patients
chronic renal failure. $\mathscr{f} p n$ Circ $\mathcal{f} 1990 ; 54: 1374-82$.

35 London JM, Guerin AP, Marchais SJ, Metivier F. Cardiomyopathy in end stage renal failure. Seminars in Dialysis 1989;2:102-7.

36 Greaves SC, Sanders GA, Gamble G, Sharpe DN, Collins JF. Cardiac function in chronic renal failure. In: Proceedings of the American Society of Nephrology 25th annual meeting and exposition, 15-18 November
1992, Baltimore (Maryland). F Am Soc Nephrol 1992; 3:3.

37 Janicki JS, Matsubara BB. Myocardial collagen and left ventricular dysfunction. In: Gaasch WH, Le Winter MM, eds. Left ventricular diastolic dysfunction. MM, eds. Left ventricular diastolic dys

38 Douglas PS, Tallant B. Hypertrophy, fibrosis and diastolic dysfunction in early canine experimental hypertension. $f$ Am Coll Cardiol 1991;17:530-6.

39 Mall G, Hunter W, Schneider J. Diffuse intermyocardiocytic fibrosis in uraemic patients. Nephrol Dial Transplant 1990;5:39-44.

40 McMahon A, Vescovo G, Dalla Libera L, Wynne DG, Fluck RJ, Harding SE, Raine AEG. Contractile dysfunction of isolated ventricular myocytes in experimental uraemia. Experimental Nephrology (in press).

41 Mall G, Rambauseck M, Neumeister A. Myocardial interstitial fibrosis in experimental uremia. Implications for cardiac compliance. Kidney Int 1988;33:804-11.

42 Rossi MA, Peres LC. Effect of captopril on the prevention and regression of myocardial cell hypertrophy and interstitial fibrosis in pressure overload cardiac hypertrophy. Am Heart $\mathcal{F}$ 1992;124(suppl 3):700-9.

43 Pauletto P, Vescovo G, Scannapieco G, Angelini A, Pessina AC, Dalla Libera L, et al. Changes in rat ventricular isomyosins with regression of cardiac hypertrophy. Hypertension 1986;8:1143-8.

44 Brilla CG, Janicki JS, Weber KT . Cardioreparative effects of lisinopril in rats with genetic hypertension and left ventricular hypertrophy. Circulation 1991;83:1771-9.

45 Huting J, Kramer W, Reitinger J, Kuhn K, Schutterle G, Wizemann V. Abnormal diastolic left ventricular filling by pulsed Doppler echocardiography in patients on continuous ambulatory peritoneal dialysis. Clin Nephrol 1991;36:21-8

46 Huting J, Alpert MA. Course of left ventricular diastolic dysfunction in end-stage renal disease on long-term continuous ambulatory peritoneal dialysis. Clin Nephrol 1993;39:81-7. 